\title{
Recent Advances in the Generation of Nitrilium Betaine 1,3-Dipoles
}

\author{
Keith Livingstone ${ }^{\text {a\# }}$ \\ Gemma Littlea \\ Craig Jamieson*a \\ a Department of Pure and Applied Chemistry, Thomas Graham \\ Building, University of Strathclyde, 295 Cathedral Street, \\ Glasgow, UK, G1 1XL. \\ \#Current Address: Organisch Chemisches Institut, Westfälische \\ Wilhelms-Universität Münster, Corrensstraße 40, 48149, \\ Münster, Germany. \\ *craig.jamieson@strath.ac.uk \\ Click here to insert a dedication.
}

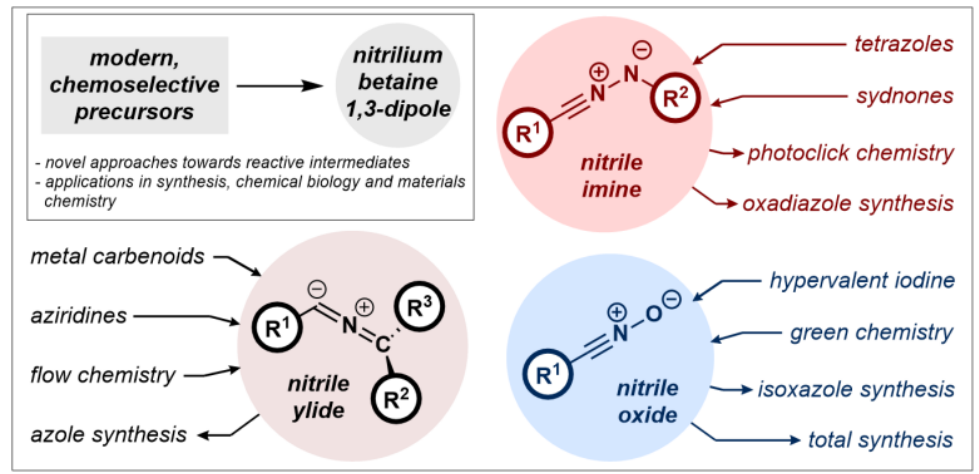

Received:
Accepted:
Published online:
DOI:
Abstract Nitrilium betaine 1,3-dipoles are ubiquitous reagents in organic
chemistry, with applications ranging from natural product synthesis to
materials science. Given the high reactivity of these zwitterionic motifs, they
are invariably generated in situ from a suitable precursor, prior to use. This
short review summarizes the recent progress in the development of modern
approaches towards the formation of these 1,3-dipoles, and their
applications within a diverse range of fields.
1. Introduction
2. Nitrile Ylides
2.1 2 H-Azirine Rearrangement
2.2 Addition of Nitriles to Carbenes
3. Nitrile Imines
3.1 2,5-Tetrazole Thermolysis
3.2 2,5-Tetrazole Photolysis
3.3 Diaryl Sydnone Photolysis
4. Nitrile Oxides
4.1 Hypervalent lodine
4.2 The Nitroso Radical
4.3 Green Chemistry Approaches
4.4 Other Methods
5. Conclusions

Key words 1,3-dipole, dipolar cycloaddition, nitrilium betaine, nitrile ylide, nitrile imine, nitrile oxide, photochemistry

\section{Introduction}

The venerable cycloaddition reaction between a 1,3-dipolar species and an appropriate dipolarophile represents a fundamental transformation within organic chemistry, with the pioneering studies of Huisgen and colleagues from the 1960s establishing a platform that has advanced from strength to strength over the past half a century. ${ }^{1}$ The formation of a broad array of heterocyclic motifs through 1,3-dipolar cycloaddition has found application in a plethora of fields, including medicinal chemistry, ${ }^{2}$ natural product synthesis, ${ }^{3}$ chemical biology ${ }^{4}$ and materials science. ${ }^{5}$ More recently, the reactivity of 1,3-dipoles with different nucleophilic motifs has also gained prominence, ${ }^{6}$ highlighting their versatility as reactive intermediates.

While more than twenty examples of 1,3-dipoles have been characterised or implicated in reaction pathways, all adhere to the same core structural scaffold of an a-b-c format, with 4 electrons shared across the $p_{\text {z }}$ orbitals of the 3 atoms (Scheme 1a).1d,1e Dipoles can then be subdivided into different categories based on the hybridisation of the central "b" atom- the allyl anions ( $\mathrm{sp}^{2}$ hybridised, with a bent structure) and the propargyl/allenyl anions (sp hydridised, with a linear structure). This review focuses on a family of propargyl/allenyl 1,3-dipoles known as the nitrilium betaines, with the general formula $\mathrm{C}=\mathrm{N}=\mathrm{X}$, comprising the nitrile ylides (NYs, $\mathrm{X}=\mathrm{C}$ ), ${ }^{7}$ nitrile imines (NIs, $\mathrm{X}=\mathrm{N}$ ), ${ }^{8}$ and nitrile oxides (NOs, $\mathrm{X}=0$ ).${ }^{9}$ The properties and applications of the nitrilium betaines are also extremely diverse, and consequently synthetic approaches towards their generation are in high demand. However, this is complicated by the extensive reactivity of these species, which often precludes their isolation and necessitating formation in situ. This article aims to highlight the advances in the generation and applications of these valuable 1,3-dipolar motifs over the past 10-15 years.

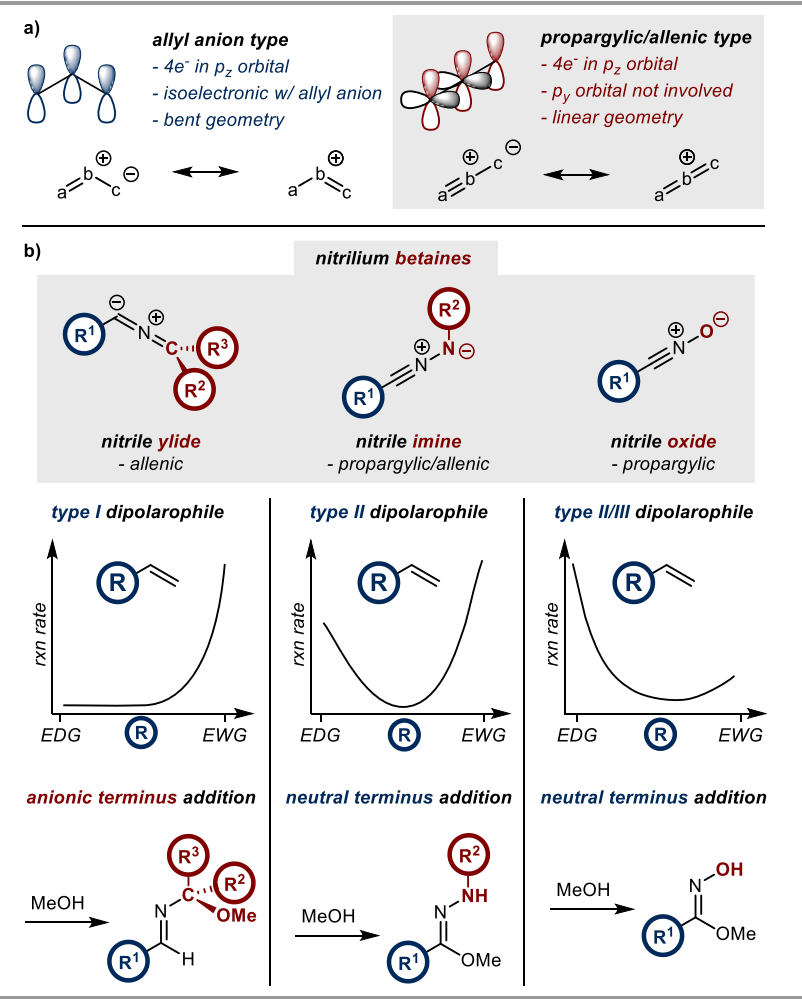

Scheme 1 (a) The two main classes of 1,3-dipole. (b) Three members of the nitrilium betaine 1,3-dipole family and their associated properties 
With the general dipole formula $\mathrm{C}=\mathrm{N}=\mathrm{C}$, there is limited literature evidence relating to the detection of the $\mathrm{NY}$ in comparison to the other two members of the nitrilium betaines. Nevertheless, this species remains a valuable tool in the formation of several $\mathrm{N}$-heterocyclic motifs. ${ }^{10}$ The NY is a relatively electron-rich dipole, and its cycloaddition with alkenes is typically under $\mathrm{NY}_{\text {номо-dipolarophile }}$ Luмо control (type I, Scheme 1b). ${ }^{11}$ This enhanced electron-density also influences the dominant resonance contributors to NY structure, with the allenic form most prominent. Many NYs also possess considerable carbenic character, and consequently may also participate in 1,1-cycloadditions. ${ }^{12}$ The impact of these resonance forms induces a more symmetrical distribution of electron density in comparison to the $\mathrm{NI}$ and the $\mathrm{NO}, 13$ and as such somewhat counterintuitively, nucleophiles may add to the anionic terminus of the NY. ${ }^{14}$

The most common approach towards NY formation is through dehydrochlorination of the corresponding imidoyl chloride. ${ }^{10,14 a}$ This method can furnish a reversible, and therefore stable, source of the dipole through treatment with a tertiary organic base such as triethylamine (Scheme 2). Alternative approaches, which have the subject of more recent development, include the rearrangement of $2 \mathrm{H}$-azirines, and addition of carbenes to nitriles.

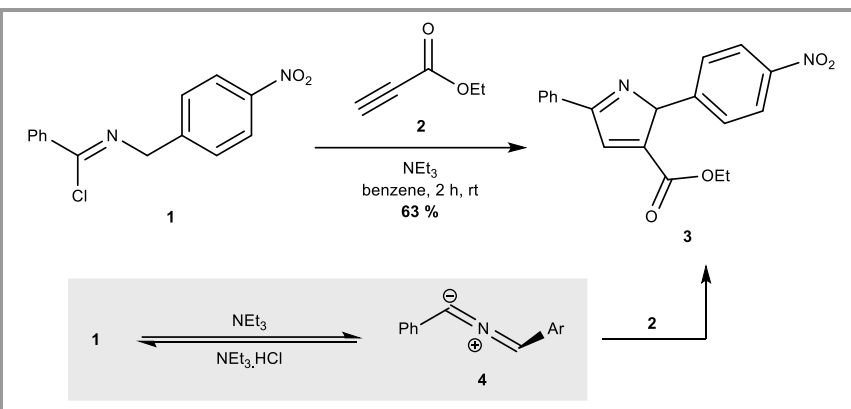

Scheme 2 The generation of NYs using imidoyl chlorides and base

\subsection{H-Azirine Rearrangement}

The rearrangement of $2 \mathrm{H}$-azirine species to afford NYs has been known for many years, with seminal reports from Padwa and Schmid in 1972.15 While thermolysis of these strained heterocycles often leads to large number of different decomposition products, ${ }^{16}$ photolysis can afford clean isomerisation to the corresponding 1,3-dipole. ${ }^{17}$ While this transformation has remained mechanistically ambiguous, ${ }^{18}$ recent computational efforts by Lui and Cao have significantly improved the understanding of this photoisomerization. ${ }^{19} 2 \mathrm{H}$ Azirines were shown to undergo an $\mathrm{n} \rightarrow \pi^{*}$ excitation to the first excited singlet state with absorption of $248 \mathrm{~nm}$ light, stimulating C-C bond cleavage (Scheme 3). Ultrafast relaxation to the ground state then afforded the corresponding NY. Both azirine substitution pattern and the wavelength of light employed ${ }^{18 b, 20}$ were found to be important factors on the efficiency of the reaction, with lower-energy light prompting cleavage of the C-N bond via the triplet excited state.

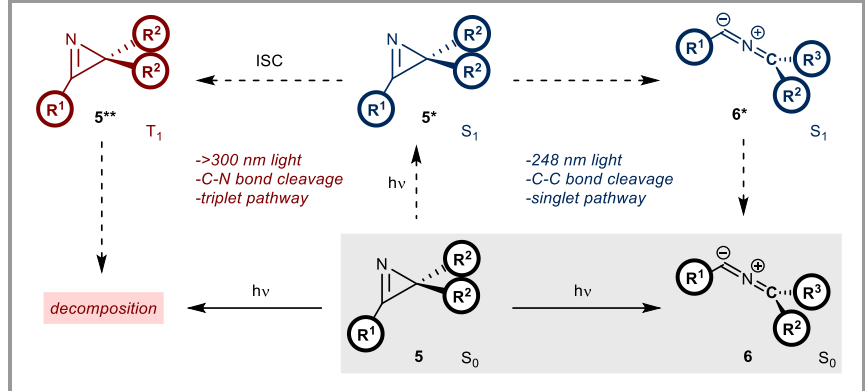

Scheme 3 Photolysis of appropriately substituted $2 \mathrm{H}$-azirines using $248 \mathrm{~nm}$ can afford access to NYs

In 2013, Kirschning reported the application of $2 \mathrm{H}$-azirine rearrangements in the formation of NYs when employing continuous flow photochemistry. ${ }^{21}$ Initial photochemical formation of the azirine from a vinyl azide starting material was followed by the desired isomerisation, with the NY trapped by several different dipolarophiles (Scheme 4).

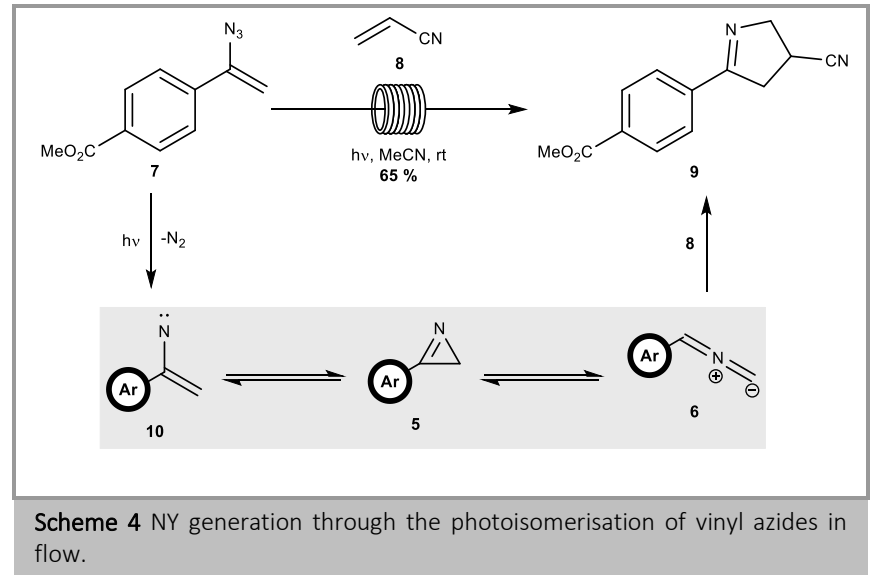

\subsection{Addition of Nitriles to Carbenes}

The treatment of an appropriate transition metal with an electron-deficient diazo species is well known to afford the corresponding metal carbenoid complex. ${ }^{22}$ The introduction of a nitrile motif in the presence of this carbene can lead to the formation of an NY 1,3-dipole, as first noted by Kende in 1982.23 Recent developments in this field of chemistry have greatly diversified both the palette of applicable transition metals, and the library of different heterocyclic products afforded by the transformation. This method of NY generation is most commonly employed during intramolecular rearrangements, involving transition metals such as rhodium, ruthenium, copper, silver, and gold (Scheme 5).24 


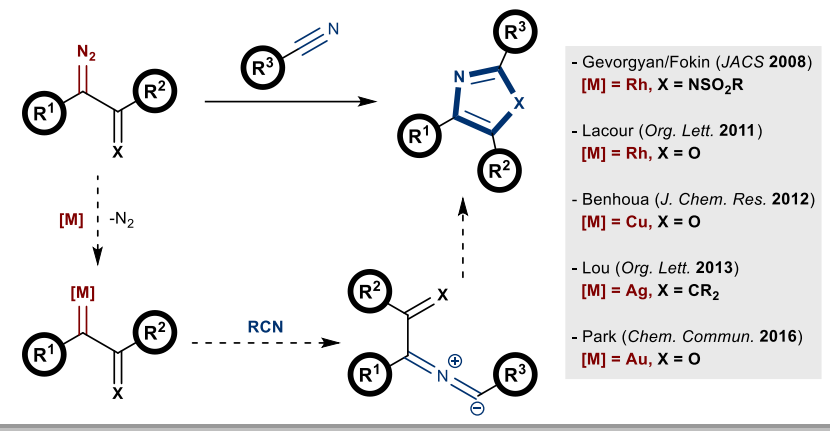

Scheme 5 The treatment metal carbenoids with nitrile motifs can generate the NY dipole, which then may undergo an intramolecular rearrangement with an adjacent $\pi$-electron system.

A less common application of this method of NY generation is in the intermolecular reaction of the resulting dipole. This manifold was first demonstrated by Liu in 2014, where goldmediated formation of $\alpha$-carbonyl NYs was quenched by the intermolecular addition of pyridine $N$-oxide derivatives (Scheme 6a). ${ }^{25}$ This was followed by a 2015 report from Ma, who employed copper in the trapping of $\alpha$-trifluoromethyl NYs with benzaldehydes (Scheme 6b). ${ }^{26}$ The capture of the 1,3-dipole with carboxylic acids that stimulate a subsequent Mummrearrangment has also been reported recently. ${ }^{27}$

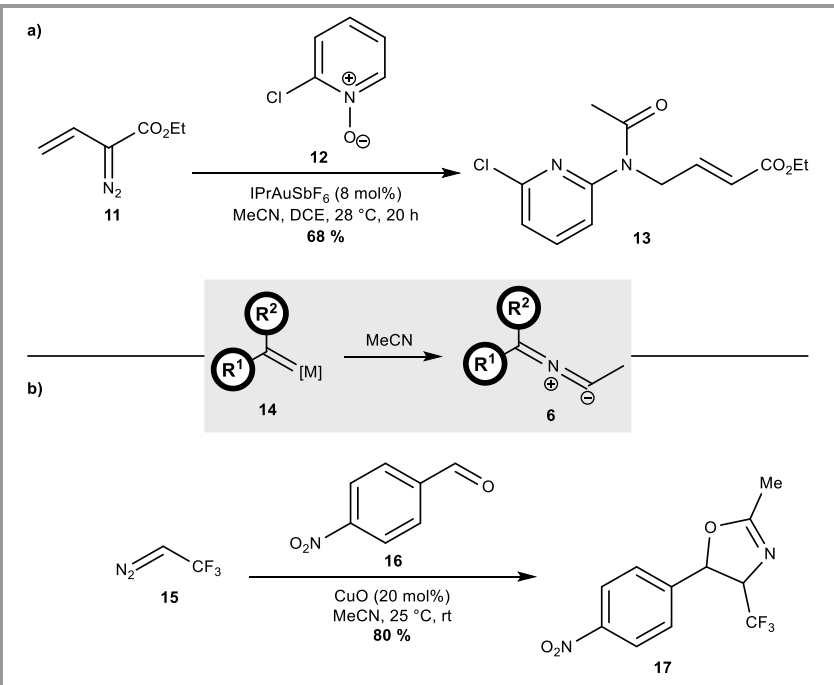

Scheme 6 The intermolecular trapping of carbene-generated NYs using nucleophiles and electrophiles.

Intermolecular 1,3-dipolar cycloadditions have also been exemplified in this field of chemistry. In an example from 2018, Bao and Wan demonstrated the synthesis of 1,2,4-triazoles through the cycloaddition of NYs and diazonium salts. ${ }^{28}$ The transformation was facilitated through a copper(I) catalyst, with a variety of $\alpha$-diazocarboxy esters, alkyl nitriles and aryl diazoniums shown to be compatible substrates (Scheme 7).

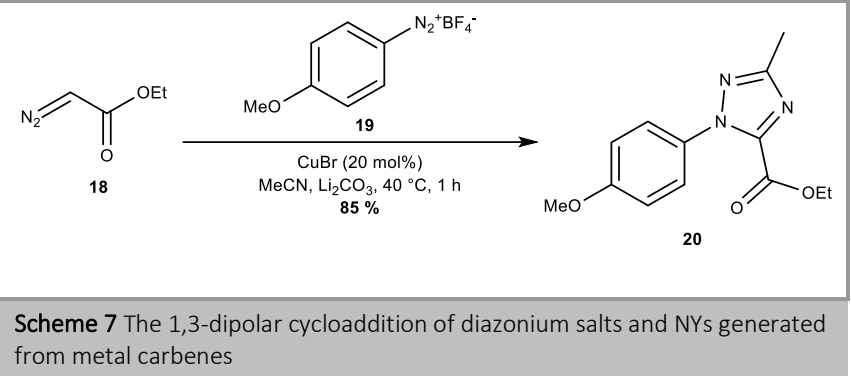

\section{Nitrile Imines}

In many ways, the NI 1,3-dipole could be considered the quintessential example of a nitrilium betaine. Due to the incorporation of a nitrogen atom at the anionic terminus, this motif often exhibits reactivity that could be consistent with either the NY or the NO, with a substantial dependency on substituents determining the inherent properties of the dipole. For example, both the allenic and propargylic resonance contributions of NIs are well-documented, with electron-rich motifs increasing the prominence of the allenic form (Scheme 1b). ${ }^{8 a}{ }^{29}$ Following Sustmann's classification, ${ }^{11}$ NIs are a type II dipolarophile, with both HOMO and LUMO mixing implicated in 1,3-dipolar cycloaddition. As a consequence, any form of electronic manipulation of the dipolarophile should increase the rate of NI cycloaddition, with ethene gas hypothetically considered the least efficient substrate.11b However, excessive lowering of the $\mathrm{NI}_{\text {номо }}$ through the inclusion of electronwithdrawing groups can, in some cases, promote type I dipole reactivity. ${ }^{30}$ In contrast to NYs, NIs react with nucleophiles through addition to the neutral terminus, owing to the increased prominence of the propargylic resonance form. ${ }^{31}$

Dehydrochlorination of hydrazonyl chlorides is the most conventional method of NI formation, in direct analogy with the NY. ${ }^{32}$ However, recent advances in controlled heterocycle decomposition have stimulated widespread application of 2,5tetrazoles and diaryl sydnones as alternative sources of the dipole.

\subsection{2,5-Tetrazole Thermolysis}

Substitution of the 2- and the 5-positions of a tetrazole motif can lead to thermal decomposition of the heterocycle at high temperatures, affording one equivalent of the corresponding NI. The generation of $\mathrm{N}_{2}$ gas as a by-product renders this transformation irreversible. Tetrazole thermolysis was first utilised by Huisgen as early as 1959 (Scheme 8a). ${ }^{33}$ Critical to this approach, as later confirmed by Baldwin, ${ }^{34}$ was the influence of the 2-substituent of the tetrazole, with increased electron-withdrawing properties enhancing the rate of tetrazole decomposition (Scheme 8b). Very recently, Murakami and coworkers have demonstrated that $N$-triflyl tetrazoles can furnish the corresponding $\mathrm{NI}$ at temperatures as low as $10{ }^{\circ} \mathrm{C}$, by successfully employing these substrates in the preparation of a library of 1,2,4-triazoles (Scheme 8c). ${ }^{33}$ Generation of the 1,3dipole in the presence of an excess of both alkyl and aryl nitriles afforded the products in good yields. 


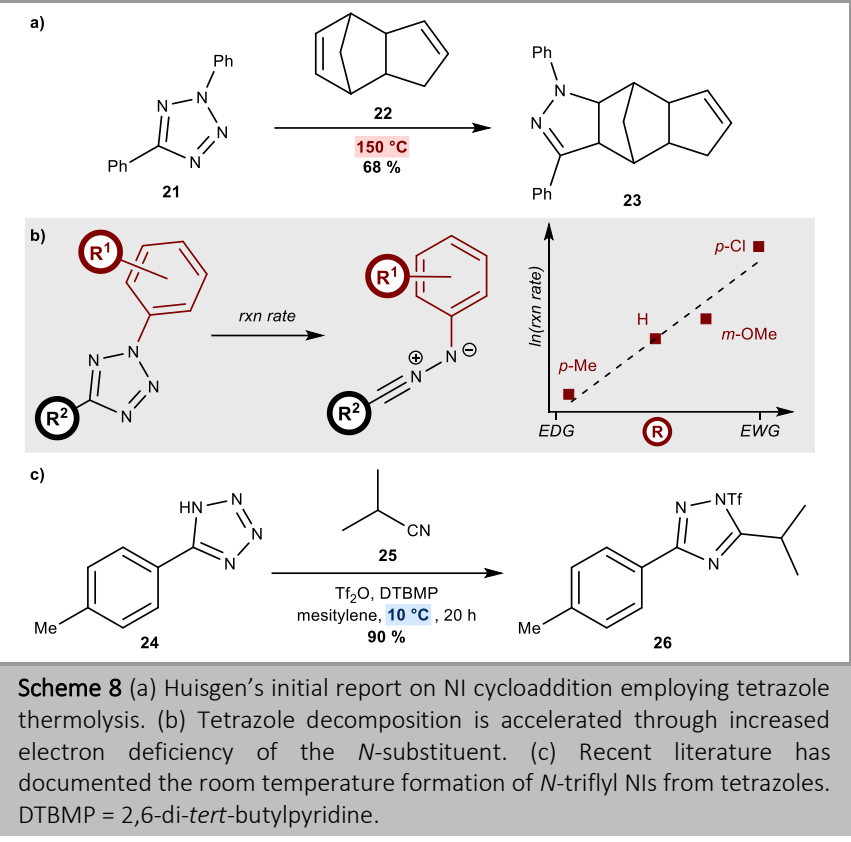

\subsection{2,5-Tetrazole Photolysis}

First disclosed in 1967,36 the photolysis of 2,5-tetrazoles to afford NIs is often a preferred approach to the thermal method owing to the relatively mild reaction conditions. UV-B light $(\lambda$ $270-330 \mathrm{~nm}$ ) is typically sufficient to facilitate the transformation at room temperature, providing the $\mathrm{N}$ -

Despite the application of this protocol for over half a century, a comprehensive mechanistic study was not reported until 2017 (Scheme 9). ${ }^{37}$ Excitation from the ground state of the tetrazole to the first singlet excited state is facilitated through the transition of an electron from a $\pi \rightarrow \pi^{*}$ orbital. Whereas excitation of $2 \mathrm{H}$-azirines was found to afford NYs directly from the singlet excited state, 2,5-tetrazoles must first undergo intersystem crossing to a triplet state prior to NI formation. As a consequence, the efficiency of dipole formation from 2,5tetrazoles is highly dependent on the degeneracy of their singlet and triplet excited states.

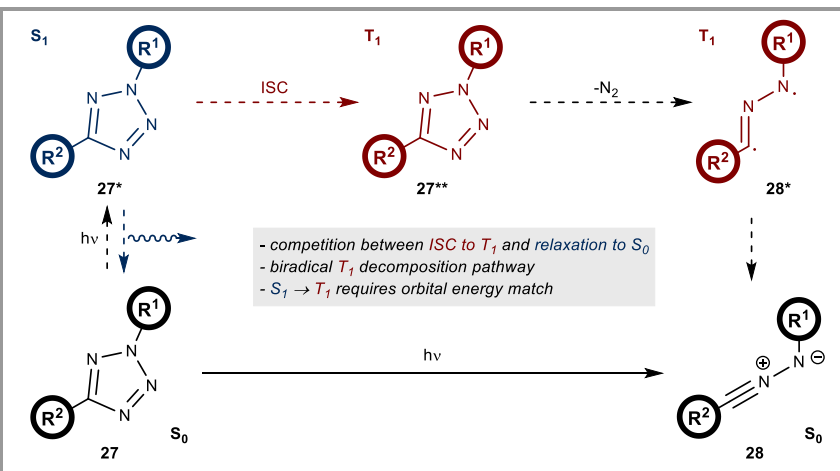

Scheme 9 Photochemical generation of the NI 1,3-dipole from 2,5-tetrazoles

Over the past 15 years, tetrazole photolysis as an NI source has captured the attention of the bioorthogonal chemistry community. Given the well-established efficiency of 1,3-dipolar cycloaddition reactions, the opportunity to generate a NI motif substituent is an aryl group. proceeds via an excited triplet state.

in the absence of any exogenous reagents other than a dipolarophile is evidently well-suited to orthogonal ligation strategies for biomolecular applications. This was first accomplished by Lin in 2008,38 and has since found further application in protein ligation, ${ }^{39}$ peptide stapling, ${ }^{40}$ and chemosensors. ${ }^{41,42}$ Recently, the reactivity of NIs with carboxylic acids has risen to prominence, with considerable application in photo-affinity labelling technologies (Scheme 10a). ${ }^{43}$

Similar ligation strategies involving NIs have also recently been employed within macromolecular chemistry and materials science. 44 Light-activated formation of the dipole and its subsequent capture has contributed greatly towards novel approaches in polymer synthesis ${ }^{45}$ and surface modification (Scheme 10b). ${ }^{46}$

In addition to its application in the liberation of NYs from azirines, flow photochemistry has also been employed in the generation of NIs from tetrazoles. This was first achieved by our own laboratory in 2019, during the development of a novel method of metal-free C-C bond formation between NIs and aryl boronic acids. ${ }^{47} \mathrm{~A}$ subsequent report bolstered the application of this emerging field through the formation of highly reactive $N$-acyl NIs in flow, which underwent intramolecular 1,5rearrangment to furnish a diverse palette of 1,3,4-oxadiazoles (Scheme 11).48 The introduction of the flow manifold was shown to significantly reduce reaction time while simultaneously improving reaction yield.

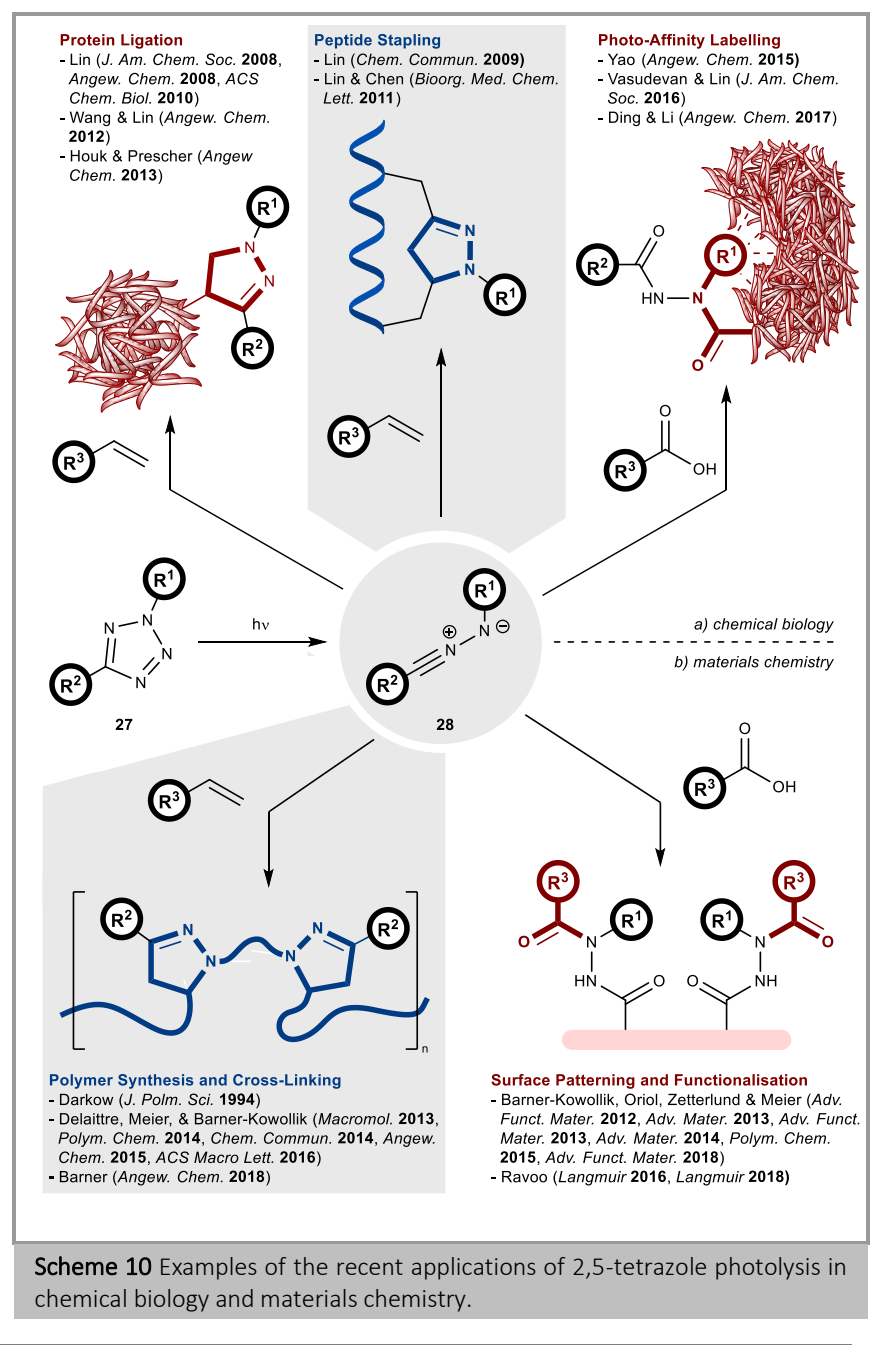

Template for SYNTHESIS (C) Thieme Stuttgart · New York ２021-04-28 
One of the primary drawbacks in the application of tetrazole photolysis as an NI source is the necessity of high-energy UV-B light. Consequently, numerous reports have contributed to the preparation of 2,5-tetrazoles with progressively higher $\lambda_{\max }$ values over the past decade. Driven primarily by the groups of Lin, ${ }^{49}$ Blinco and Barner-Kowollik, ${ }^{50}$ this research has afforded several different approaches towards lowering this activation energy, including scaffold conjugation, ${ }^{49-d, 50 a}$ two-photon excitation, ${ }^{49 \mathrm{e}}$ and the application of upconversion nanoparticles (Scheme 12).50b

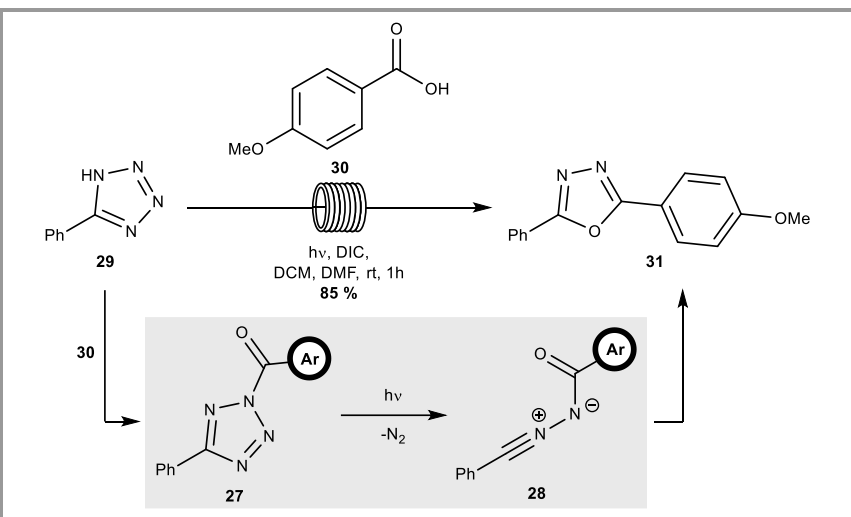

Scheme 11 Flow photochemistry can be utilised in the manipulation of highly reactive $\mathrm{NI}$ species. DIC $=N, N^{\prime}$-Diisopropylcarbodiimide.

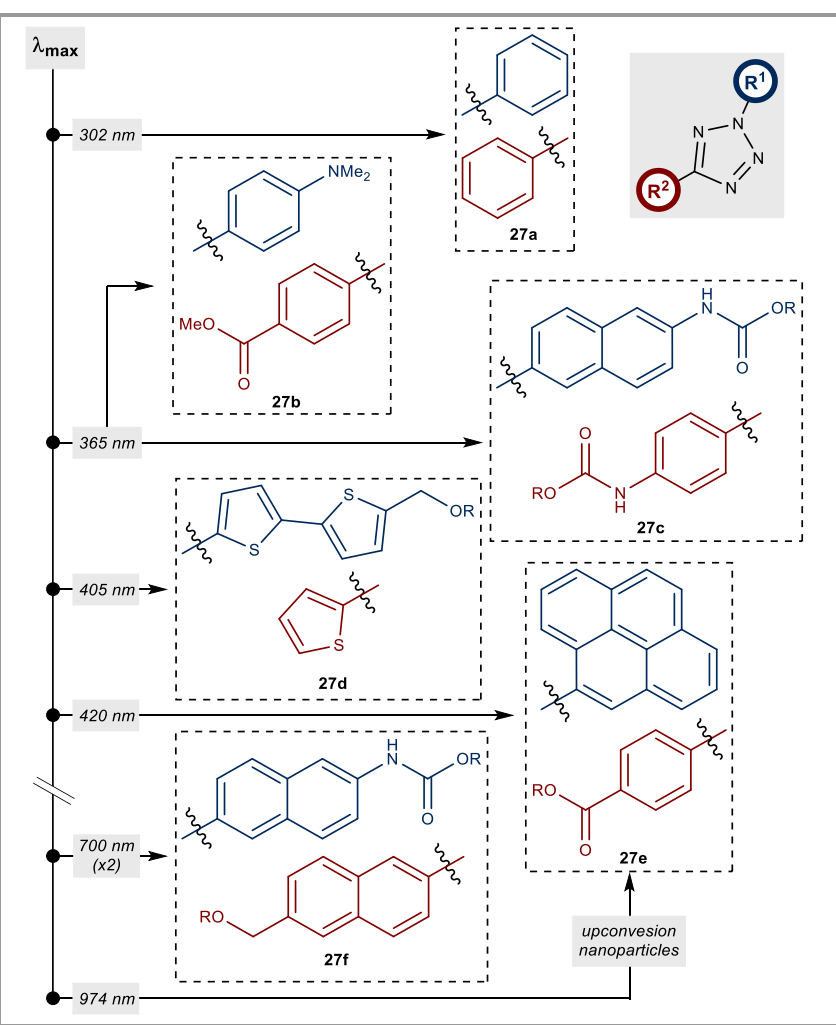

Scheme 12 Modification of the functional groups augmenting the tetrazole nucleus may have a substantial impact on the $\lambda_{\max }$ of the moiety.

\subsection{Diaryl Sydnone Photolysis}

The sydnone motif is an intriguing structure, widely regarded as the most well-studied example of the mesoionic heterocycle substrate class. ${ }^{51}$ The species is characterised by a zwitterionic five-membered ring, with a pendant oxygen atom at the 5- position. Sydnones are known to undergo cycloaddition reactions with dipolarophiles under thermal conditions, with subsequent loss of $\mathrm{CO}_{2}$ affording pyrazoline cycloadducts. ${ }^{52}$

As first reported by Piek and co-workers in 1966, diaryl sydnones are also photoreactive. ${ }^{53}$ Ensuing literature reports soon intimated the generation of a NI 1,3-dipole following decarboxylation upon exposure to UV light (Scheme 13). ${ }^{54}$ Despite furnishing the same product upon combination with a dipolarophile, this represented a distinct deviation from the mechanism of thermal sydnone cycloadditions, where the NI is not implicated.

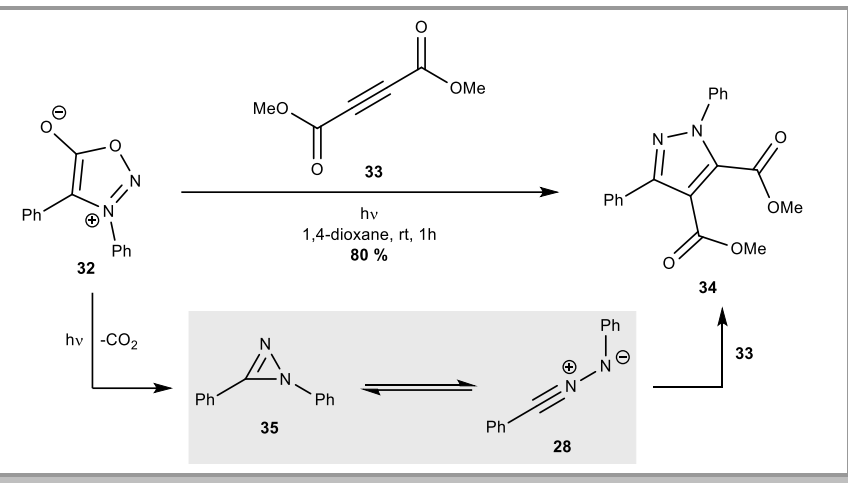

Scheme 13 Photochemical generation NIs through diaryl sydnones.

Despite the considerable applicability of the methodology, very little literature activity has been reported on the photolysis of diaryl sydnones since the 1970s. Recently, however, this method of NI formation has been re-established through the work of Yu and co-workers. ${ }^{55}$ The generation of the dipole from 3,4-diaryl sydnones has been employed in several bioorthogonal ligation processes, in addition to peptide stapling. A library of strained alkene, alkyne and azobenzene dipolarophiles have demonstrated compatibility within this manifold. Owing to the strained ortho-configuration of the two aromatic motifs of the sydnone, thermal cycloaddition is disfavoured, promoting lightactivated pyrazoline formation via the NI intermediate (Scheme 14).

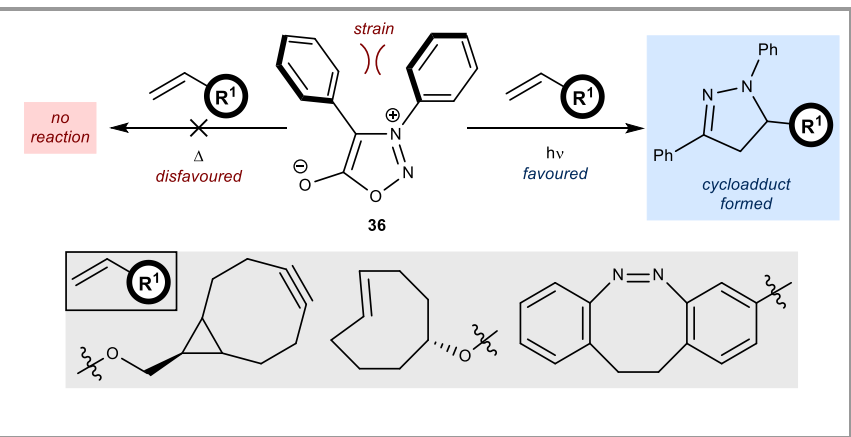

Scheme 14 The ring strain induced by the ortho relationship between the pendant aryl motifs of 3,4-sydnones promotes cycloaddition through a NI intermediate.

\section{Nitrile Oxides}

The NO 1,3-dipole represents the most widely studied example of the nitrilium betaine family, serving as an accessible isooxazoline precursor in a number of reports.1d,3a,9b,56 Due to the incorporation of a strongly electronegative oxygen atom at the anionic terminus, the NO shares several key properties with 
electron-deficient examples of the closely related NI species, and both exist as propargylic linear structures. ${ }^{8,9}$ While this motif often exhibits reactivity consistent with NIs, the NO should be treated as an electrophilic dipole, with lower FMO energies than any other example discussed thus far. The dipole is classically defined as type II in accordance with Sustmann's classification system, ${ }^{11}$ however in many cases orbital mixing with electronrich alkenes is considerably more efficient, predominantly proceeding under NOLumo-dipolarophilеномо control (type III, Scheme 1b). Consequently, electron-donating dipolarophile substituents significantly enhance the rate of NO cycloaddition. Unlike the electron-rich NY, the electron-deficient nature of the NO directs reactivity of nucleophiles to the neutral carbon terminus. ${ }^{57}$

While other nitrilium betaines primarily decompose in the absence of a suitable reaction partner, most NO species are prone to dimerization, affording 1,2,5-oxadiazole-2-oxides. ${ }^{58}$ NOs also exhibit marginally improved energetic stability relative to NYs and NIs, and stable examples of the species can be isolated at room temperature with the introduction of appropriate steric occlusion (Scheme 15a). ${ }^{56 b, 59}$ It should be noted that examples of stable NI derivatives are also known, although much less common. ${ }^{8 a, 60}$

There are three fundamental approaches towards the generation of NO species: dehydrochlorination of the associated hydroximoyl chloride species, $9 \mathrm{~b}, 61,62$ the oxidation of aldoximes (Scheme 15b), $61,62 \mathrm{~d}, 63$ or the dehydration of nitroalkanes. ${ }^{9 \mathrm{~b}, 62 \mathrm{j}, 64}$ Due to the prevalence of NO 1,3-dipolar cycloaddition in several fields of synthetic organic chemistry, recent literature has emphasized the development of milder reaction conditions towards this valuable species. Alternative methods include the oxidation of oximes using hypervalent iodine reagents, utilising the nitroso radical as a NO source, the advancements of green protocols for the generation of NOs, and some further methods that have been also been developed. These are discussed in the following sections.

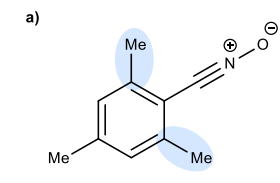

$37 a$

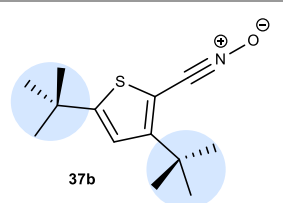

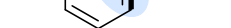
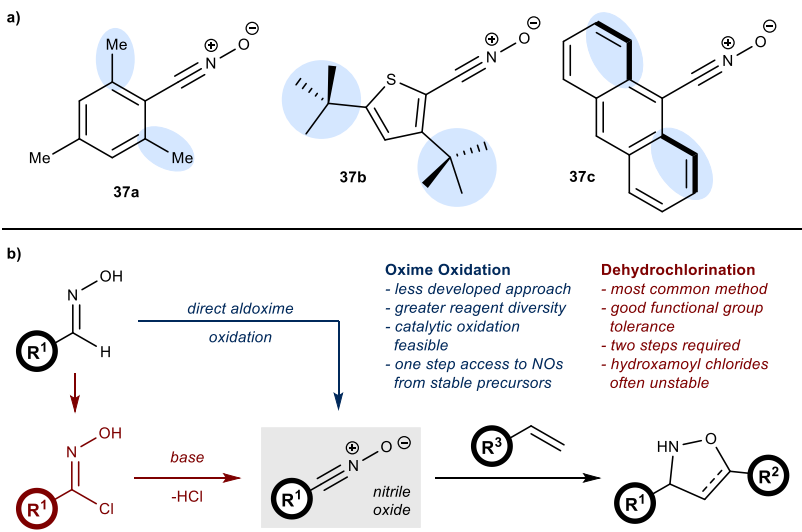

Scheme 15 (a) Several NO species may be isolated under ambient under ambient conditions through the incorporation of appropriately bulky substituents. (b) Two of the most common methods of NO formation originate from manipulation of the aldoxime motif.

\subsection{Hypervalent lodine}

Traditional methods towards the preparation of NOs have utilised the iterative halogenation/dehydrohalogenation of aldoximes as outlined above. However, this approach requires multiple steps, and necessitates the generation of a reactive hydroximoyl chloride intermediate, often unstable under ambient conditions. ${ }^{62 f, 65}$ The liberation of the NO dipole through the direct oxidation of the corresponding aldoxime represents a much more synthetically tractable approach.

In 2004, Das identified the application of hypervalent iodine as the oxidant in this valuable transformation. ${ }^{66}$ The introduction of hypervalent iodine reagents has since emerged as an attractive method of dipole formation due to their ubiquity, low toxicity, ease of handling and facile reactivity. ${ }^{67}$ In the late 2000s, the application of this reaction manifold was further refined, culminating in NO formation under extremely mild conditions (Scheme 16a). ${ }^{65 c, 68}$ Hypervalent iodine reagents used for the generation of NO species have also been exemplified by its application in the synthesis of the Cortistatin family of natural products in 2009, and in the construction of (-)Mitrephorone in 2020. In both cases, facile NO liberation afforded heavily functionalised heterocyclic motifs critical to formation of the complex biomolecules (Scheme 16b). ${ }^{69}$

The overall atom-economy and environmental impact of this protocol was substantially improved in 2013, with the application of catalytic quantities of iodine through the introduction of a terminal oxidant. Simultaneous reports from the Yan and Zhdankin laboratories achieved NO formation via the introduction of $m C P B A$ or Oxone ${ }^{\circledR}$ to regenerate the active I(III) species following aldoxime oxidation (Scheme 17). ${ }^{70}$ Catalytic iodine has since been employed in the synthesis of oxadiazoles and isoxazolines through NO cycloaddition, employing trifluoromethanesulfonic acid as an additive. ${ }^{71}$ 

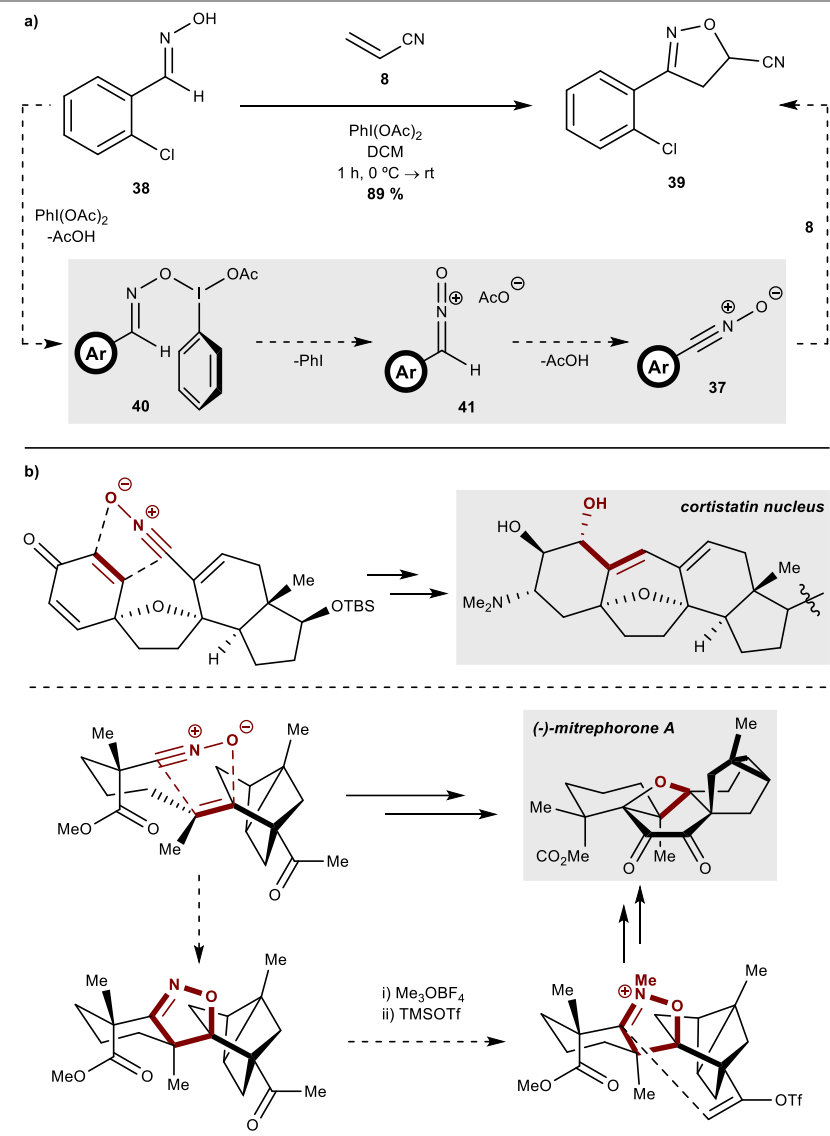

Scheme 16 (a) The oxidation of aldoximes by an iodine(III) species. (b) The application of NOs generated through hypervalent iodine oxidation in total synthesis.

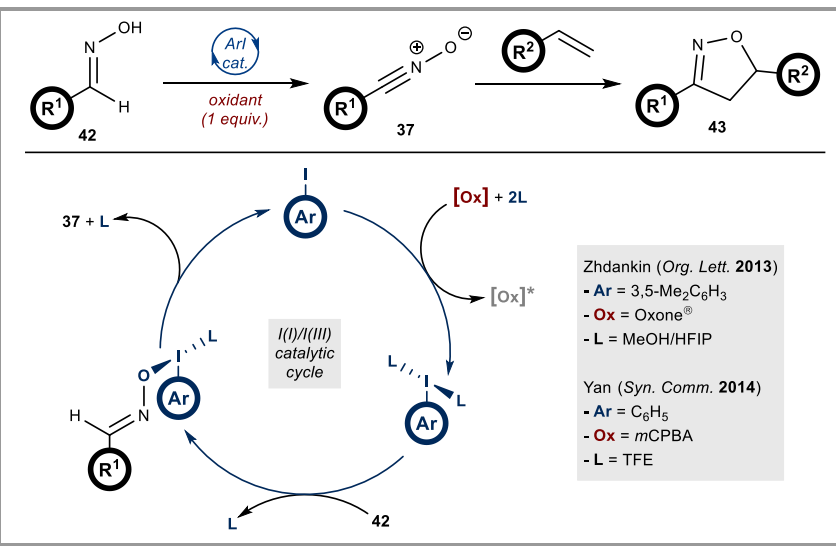

Scheme 17 The formation of NOs employing catalytic quantities of I(III) and a terminal oxidant. HFIP = hexafluoroisopropanol; TFE = trifluoroethanol.

\subsection{The Nitroso Radical}

As discussed in Section 2.2, the NY 1,3-dipole can be generated through the interaction of a nitrile motif and a metal carbenoid, with carbene insertion affording the nitrilium betaine. As first reported by Wan and coworkers in 2017, similar protocols may be employed as a source of NOs, whereby the trapping of the carbene by a nitroso radical may generate the dipole (Scheme 18). ${ }^{72}$ This was accomplished via the in situ fragmentation of tert-butyl nitrite in the presence of a copper carbene complex, with the resulting NOs employed in the construction of a diverse library of isoxazolines under mild conditions. ${ }^{72 a}$ In 2018, the
Wan laboratory expanded the scope of this procedure, incorporating ß-keto esters as an alternative dipolarophile, to generate densely substituted isoxazoles. ${ }^{72 b}$ Similar reactivity was demonstrated by Wang in 2019, with the application of alkyne derivatives to trap the nitrilium betaine species, forming substituted isoxazoles. ${ }^{73}$

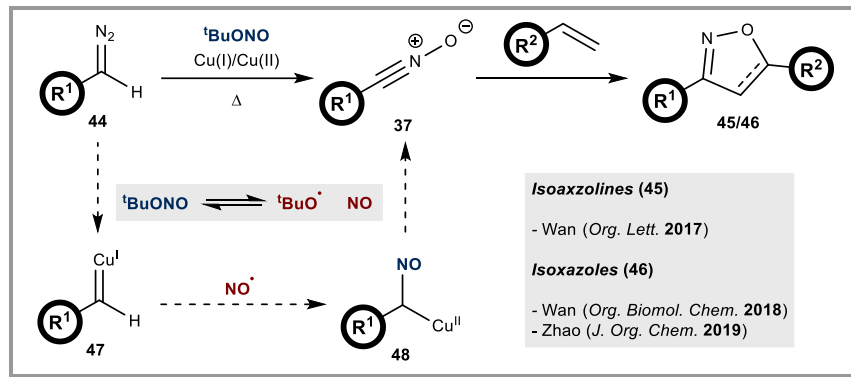

Scheme 18 Metal carbenoids may combine with the nitroso radical in situ to afford the NO 1,3-dipole.

While all above examples required prior isolation of preformed diazo components, in situ generation of these compounds is also achievable. Very recently, $\mathrm{Hu}$ and coworkers disclosed an oxidative NO cycloaddition employing commercially available amines with tert-butyl nitrite and dipolarophiles to form isoxazoline or isoxazole motifs in the presence of zinc bromide and a rhodium catalyst (Scheme 19a). ${ }^{74}$ This elegant one-pot procedure represents a valuable approach towards NO formation due to the utilisation of abundant and unreactive starting materials. Additionally, this protocol demonstrates impressive chemoselectivity, with the generation of several highly reactive intermediate species over the course of the reaction pathway. It is proposed that tert-butyl nitrite performs a dual role in the reaction, by facilitating the oxidation of the amine to the corresponding diazo species, which then furnishes the NO 1,3-dipole in an analogous manner to the mechanism described above. The NO was then trapped by several dipolarophiles, highlighting the applicability of the protocol.

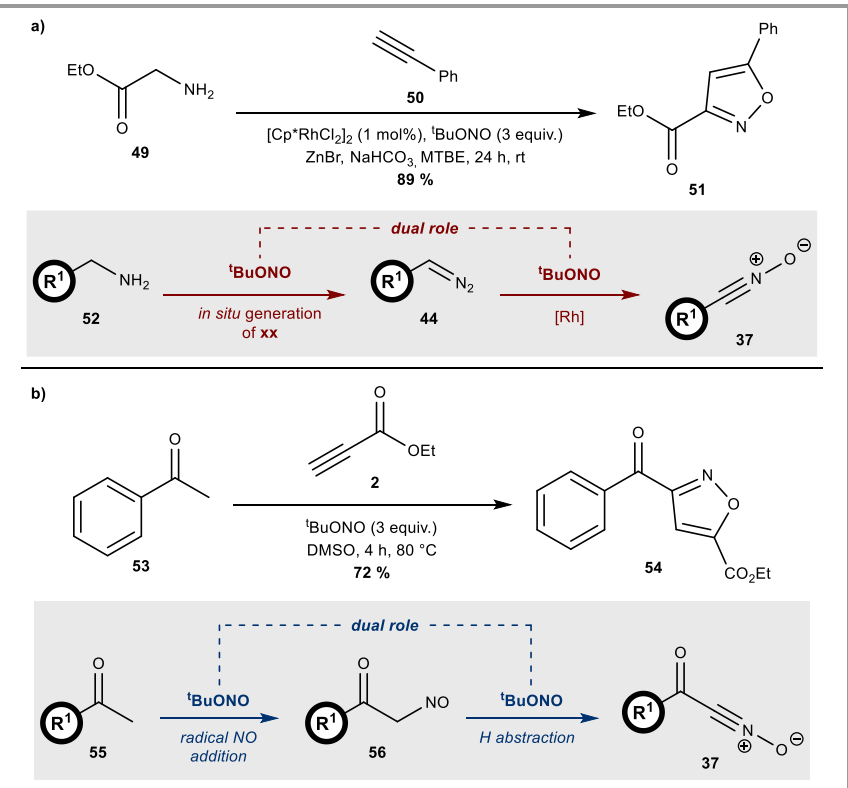

Scheme 19 (a) The generation of NOs from metal carbenes with the in situ formation of the diazo precursor, facilitated by the dual role of tert-butyl nitrite. (b) Nitrosylation of methyl ketones can furnish C-acyl NOs in the 


\section{presence of organic nitrites.}

Zhang disclosed an alternative method for the liberation of NOs in situ in 2019, utilising tert-butyl nitrite and methyl ketones (Scheme 19b). ${ }^{75}$ This $\mathrm{C}\left(\mathrm{sp}^{3}\right)-\mathrm{H}$ bond functionalization is an attractive alternative to the above methodologies as it does not require the use of transition metal catalysts, while further reinforcing the versatility of organic nitrite reagents and their applications in NO formation.

\subsection{Green Chemistry Approaches}

The development of more environmentally friendly reagents and reaction conditions is of contemporary importance to the field of organic chemistry, and indeed this ethos is also apparent in 1,3-dipolar cycloaddition methodology. In particular, increasing interest in NO chemistry has led to various developments in more sustainable approaches towards its generation and applications in $\mathrm{N}, \mathrm{O}$-heterocycle synthesis. ${ }^{76,77} \mathrm{In}$ one such example from 2010, Yao introduced a protocol detailing the construction of tricyclic isoxazole derivatives involving NO generation under aqueous solvent conditions (Scheme 20a).76a The application of this "on water" approach to 1,3-dipole generation mitigates the financial and environmental impacts of a more conventional organic solvent. NO formation was accomplished using direct oxidation of an aldoxime by an iodine(III) reagent (Section 4.1). Similar methodology has also been reported by Kittakoop, through the generation of the dipole from hydroximoyl halides in aqueous solutions containing an acidic buffer.76b Cycloadditions conducted under these conditions proceeded with excellent regio- and stereoselectivity to furnish a broad library of isoxazolines and oxadiazoles.

In contrast to the modification of the solvent system, the sustainability of NO generation may also be improved through the introduction of less hazardous reagents. A recent report by Tong disclosed a transformation outlining dipole formation through aldoxime oxidation using Oxone ${ }^{\circledR}$ and $\mathrm{NaCl}^{77}$ The relative abundance and high stability of these additives is a considerable advantage over other oxidising agents that are commonly employed in NO synthesis. The overall efficiency of this protocol was further improved through the application of a multicomponent reaction of aldehydes, hydroxylamine, and alkenes for the synthesis of isoxazolines via a NO intermediate.

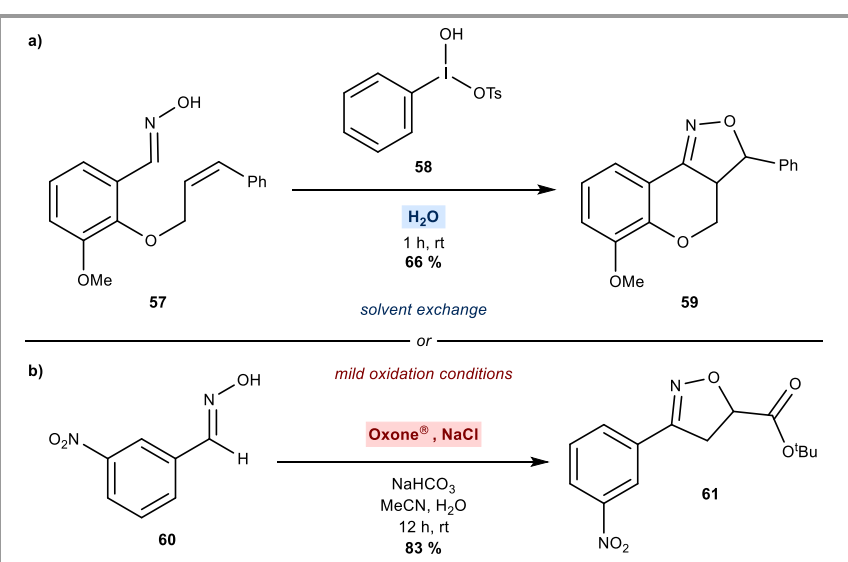

Scheme 20 (a) The generation and subsequent reactivity of NOs under aqueous conditions. (b) The application of mild oxidation conditions may have a significant impact on the sustainability of NO formation protocols.

\subsection{Other Approaches}

While conventional NO release from hydroximoyl halides is one of the most established routes towards the 1,3-dipole, recent literature examples have disclosed similar motifs that employ alternative leaving groups in an effort to improve their stability and general compatibility with other moieties. In 2000, Carreira developed a dehydrative protocol for the generation of NOs from $O$-silylated hydroxamic acids upon treatment with triflic anhydride (Scheme 21). ${ }^{78}$ However, despite the apparent applicability of this methodology, no further reports of this approach towards NO formation appeared until 2019, when Bonifazi adapted the methodology to afford the regioselective preparation of 3,5-disubstituted isoxazoles from a NO intermediate. ${ }^{79}$ Quantitative generation of the 1,3-dipole has reportedly been accomplished in under 3 minutes when employing this protocol.

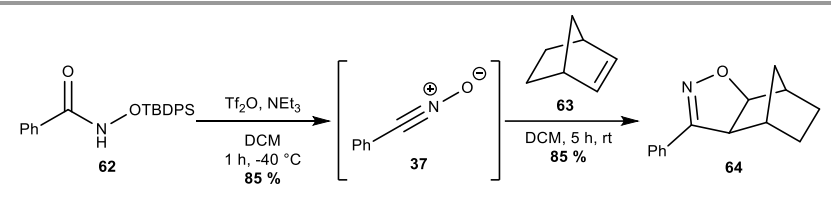

Scheme 21 The triflation of hydroxamic acid derivates and their subsequent desilyation has been exemplified as a reliable source of the NO dipole.

NO generation may also be achieved via decarboxylation enabled by photoredox catalysis. As first disclosed by Leonori in 2016, two consecutive single-electron transfer processes stimulated by a ruthenium(II) photocatalyst and blue LEDs afforded the dipole from a selection of $N$-hydroxyimino acid derivatives (Scheme 22). ${ }^{80}$ The NO was subsequently employed in the synthesis of a multitude of five-membered heterocyclic motifs.

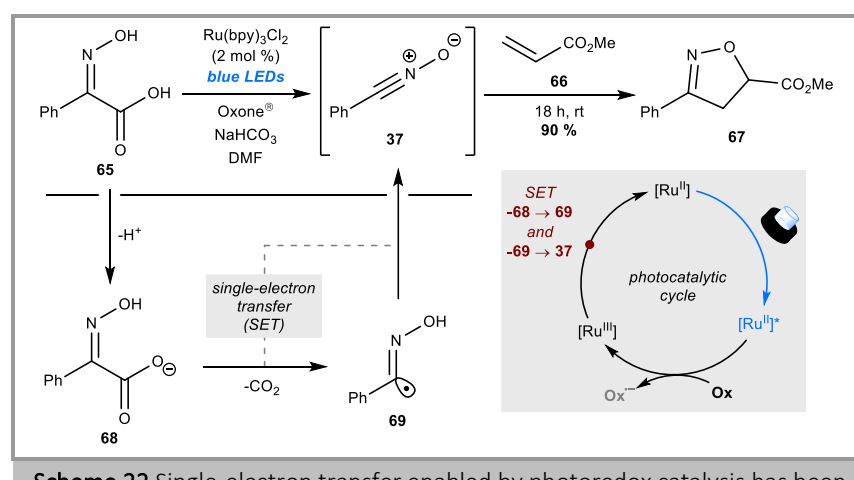

Scheme 22 Single-electron transfer enabled by photoredox catalysis has been shown to furnish NOs from relatively inert $N$-hydroxyimino acid precursors.

\section{Conclusions}

The chemistry of the nitrilium betaine 1,3-dipoles has enjoyed a raft of different developments over the past 60 years, with multiple applications in a diverse array of disciplines reinforcing the remarkable versatility of this unique family of reactive intermediates. As demonstrated by the considerable literature activity over the past 15 years, research into the generation of these compounds remains a fruitful area of investigation, necessitated primarily by the continued application of the NI and NO dipoles in ligation chemistry and total synthesis, respectively. It is likely that the substantial potential 
applications of these species will continue to further advance the development of different approaches towards nitrilium betaine formation well into the next decade.

\section{Funding Information}

We gratefully acknowledge support from the University of Strathclyde (studentship to GL) and the EPSRC for funding via Prosperity Partnership EP/S035990/1

\section{References}

(1) (a) Huisgen, R. Angew. Chem. Int. Ed. 1963, 2, 565. (b) Huisgen, R. Angew. Chem. Int. Ed. 1963, 2, 633. (c) Padwa, A. Angew. Chem. Int. Ed. 1976, 15, 123. (d) Padwa, A. 1,3-Dipolar Cycloaddition Chemistry; Wiley: New York, 1984. (e) Gothelf, K. V.; Jørgensen, K. A. Chem. Rev. 1998, 98, 863. (f) Breugst, M.; Reissig, H-U. Angew. Chem. Int. Ed. 2020, 59, 12293.

(2) (a) Tron, G. C.; Pirali, T.; Billington, R. A.; Canonico, P. L.; Sorba, G.; Genazzani, A. A. Med. Res. Rev. 2007, 28, 278. (b) Berthet, M.; Cheviet, T.; Dujardin, G.; Parrot, I.; Martinez, J. Chem. Rev. 2016, 116, 15235. (c) Jiang, X.; Hao, X.; Jing, L.; Wu, G.; Kang, D.; Liu, X.; Yhan, P. Expert. Opin. Drug Discov. 2019, 14, 779.

(3) (a) Padwa, A.; Pearson, W. H. Synthetic Applications of 1,3-Dipolar Cycloaddition Chemistry Toward Heterocycles and Natural Products; Wiley: Hoboken, 2002. (b) Padwa, A.; Bur, S. In Advances in Heterocyclic Chemistry, Vol. 119; Scriven, E. F. V.; Ramsden, C. A., Ed.; Elsevier: Amsterdam, 2016, 241. (c) Padwa, A. ARKIVOC 2018, 4, 23.

(4) (a) Amblard, F.; Cho, J. H.; Schinazi, R. F. Chem. Rev. 2009, 109, 4207. (b) Meyer, J.-P.; Adumeau, P.; Lewis, J. S.; Zeglis, B. M. Bioconj. Chem. 2016, 27, 2791. (c) Agnew, H. D.; Coppock, M. B.; Idso, M. N.; Lai, B. T.; Liang, J.; McCarthy-Torrens, A. M.; Warren, C.; Heath, J. R. Chem. Rev. 2019, 119, 9950.

(5) (a) Delaittre, G.; Guimard, N. K. ; Barner-Kowollik, C. Acc. Chem. Res. 2015, 48, 1296. (b) Castro, V.; Rodríguez, H.; Albericio, F. ACS Comb. Sci. 2016, 18, 1. (c) Takata, T.; Koyama, Y.; Sogawa, H. In Polymer Chemistry, Vol. 30; Qin, A.; Tang, B. Z., Ed.; RSC: London, 2018, 122.

(6) (a) Nguyen, M. T.; Malone, S.; Hegarty, A. F.; Williams, I. I. J. Org Chem. 1991, 56, 3683. (b) Zhang, C.; Seidel, D. J. Am. Chem. Soc. 2010, 132, 1798. (c) Banert, K.; Pester, T. Angew. Chem. Int. Ed. 2020, 59, 12315. (d) Livingstone, K.; Bertrand, S.; Kennedy, A. R.; Jamieson, C. Chem. Eur. J. 2020, 26, 10591.

(7) Escolano, C.; Duque, M. D.; Vazquez, S. Curr. Org. Chem. 2007, 11, 741.

(8) (a) Bertrand, G.; Wentrup, C. Angew. Chem. Int. Ed. 1994, 33, 527. (b) Jamieson, C.; Livingstone, K. The Nitrile Imine 1,3-Dipole: Properties, Reactivity and Applications; Springer International Publishing: Cham, 2020.

(9) (a) Grundmann, C. In Organische Chemie: Fortschritte der Chemischen Forschung, Vol. 7; Springer: Berlin, Heidelberg, 1966, 62. (b) Belen'kii, L. I. In Nitrile Oxides, Nitrones, and Nitronates in Organic Synthesis: Novel Strategies in Synthesis; Wiley: Hoboken, 2008, 1.

(10) (a) Kiyoshi, T.; Hiroki, D; Keiryo, M. Chem. Lett. 1983, 12, 1463. (b) Tian, W.-S.; Livinghouse, T. J. Chem. Soc., Chem. Commun. 1989, 819. (c) Yoo, C. L.; Olmstead, M. M.; Tantillo, D. J.; Kurth, M. J. 2006, 47, 477. (d) Melša, P.; Čajan, M.; Havlas, Z.; Mazal, C. J. Org. Chem. 2008, 73, 3032. (e) Sibi, M. P.; Soeta, T.; Jasperse, C. P. Org. Lett. 2009, 11, 5366.

(11) (a) Sustmann, R. Tetrahedron Lett. 1971, 12, 2717. (b) Sustmann, R. Pure Appl. Chem. 1974, 40, 569.

(12) (a) Padwa, A.; Carlsen, P. H. J. J. Am. Chem. Soc. 1975, 97, 3862. (b) Padwa, A.; Carlsen, P. H. J. J. Org. Chem. 1976, 41, 180.

(13) Bunge, K; Huisgen, R.; Raab, R. Chem. Ber. 1972, 105, 1296.

(14) (a) Huisgen, R.; Stangl, H.; Sturm, H. J.; Wagenhofer, H. Angew. Chem. Int. Ed. Engl. 1962, 1, 50. (b) R. Huisgen; Stangl, H.; Sturm, H. J.; Raab, R., Bunge, K. Chem. Ber. 1972, 105, 1258.
(15) (a) Padwa, A.; Smolanoff, J. J. Am. Chem. Soc. 1971, 93, 548. (b) Giezendanner, H.; Märky, M.; Jackson, B.; Hansen, H.-J.; Schmid, H. Helv. Chim. Acta 1972, 55, 745. (c) Gakis, N.; Märky, M.; Hansen, H.-J.; Schmid, H. Helv. Chem. Acta. 1972, 55, 748.

(16) Wendling, L. A.; Bergman, R. G. J. Org. Chem. 1976, 41, 831.

(17) Naito, I.; Morihara, H.; Ishida, A.; Takamuku, S.; Isomura, K.; Taniguchi, H. Bull. Chem. Soc. Jpn. 1991, 64, 2757.

(18) (a) Bornemann, C.; Klessinger, M. Chem. Phys. 2000, 259, 263. (b) Inui, H.; Murata, S. Chem. Lett. 2001, 30, 832.

(19) Lui, Y.; Guan, P.; Wang, Y.; Liu, L.; Cao, J. J. Phys. Chem. A 2015, 119 67.

(20) Inui, H.; Murata, S. J. Am. Chem. Soc. 2005, 127, 2628

(21) Cludius-Brandt, S.; Kupracz, L.; Kirschning, A. Beilstein J. Org. Chem. 2013, 9, 1745.

(22) (a) Doyle, M. P.; McKervey, M. A.; Tao, Y. Modern Catalytic Methods for Organic Synthesis with Diazo Compounds; Wiley: New York, 1998. (b) Dörwald, F. Z. Metal Carbenes in Organic Synthesis; Wiley-VCH: Weinheim, 1999.

(23) Kende, A. S.; Hebeisen, P.; Sanfilippo, P. J.; Toder, B.H. J. Am. Chem. Soc. 1982, 104, 4244

(24) (a) Horneff, T.; Chuprakov, S.; Chernyak, N.; Gevorgyan, V.; Foken, V. F. J. Am. Chem. Soc. 2008, 130, 14972. (b) Austeri, M.; Rix, D.; Zeghida, W.; Lacour, J. Org. Lett. 2011, 13, 1394. (c) Bendedouche, C. K.; Benhaoua, H. J. Chem. Res. 2012, 36, 149. (d) Billedeau, R. J.; Klein, K. R.; Kaplan, D.; Lou, Y. Org. Lett. 2013, 15, 1421. (e) Loy, N. S. Y.; Choi, S.; Kim, S.; Park, C.-M. Chem. Commun. 2016, 52, 7336.

(25) Karad, S. N.; Liu, R-S. Angew. Chem. Int. Ed. 2014, 53, 5444.

(26) Cai, A.-J.; Zheng, Y.; Ma, J.-A. Chem Commun. 2015, 51, 8946.

(27) Chen, J.; Shao, Y.; Ma, L.; Ma, M.; Wan, X. Org. Biomol. Chem. 2016, $14,10723$.

(28) Li, H.; Wu, X.; Hao, W.; Li, H.; Zhao, Y.; Wang, Y.; Lian, P.; Zheng, Y.; Bao, X.; Wan, X. Org. Lett. 2018, 17, 5224.

(29) (a) Wong, M. W.; Wentrup, C. J. Am. Chem. Soc. 1993, 115, 7743. (b) Fauré, J.-L.; Réau, R.; Wong, M. W.; Koch, R.; Wentrup, C.; Bertrand, G. J. Am. Chem. Soc. 1997, 119, 2819. (c) Bégué, D.; Qiao, G. G.; Wentrup, C. J. Am. Chem. Soc. 2012, 134, 5339.

(30) Houk, K. N.; Sims, J.; Watts, C. R.; Luskus, L. J. J. Am. Chem. Soc. 1973, 95, 7301.

(31) Huisgen, R.; Sauer, J.; Seidel, M. Chem. Ber. 1961, 94, 2503.

(32) For recent examples, see: (a) Smedley, C. J.; Li, G.; Barrow, A. S.; Gialelis, T. L.; Giel, M.-C.; Ottonello, A.; Cheng, Y.; Kitamura, S.; Wolan, D. W.; Sharpless, K. B.; Moses, J. E. Angew. Chem. Int. Ed. 2020, 59, 12460. (b) Ledovskaya, M. S.; Voronin, V. V.; Polynski, M. V.; Lebedev, A. N.; Ananikov, V. P. Eur. J. Org. Chem. 2020, 4571. (c) Su, Y.; Ma, C.; Zhao, Y.; Yang, C.; Feng, Y.; Wang, K.-H.; Huang, D.; Huo, C.; Hu, Y. Tetrahedron 2020, 76, 131355. (d) Yavari, I.; Khaledian, O. Synthesis 2020, 52, 1379. (e) Su, Y.; Zhao, Y.; Chang, B.; Zhao, X.; Zhang, R.; Liu, X.; Huang, D.; Wang, K.-H.; Huo, C.; Hu, Y. J. Org. Chem. 2019, 84, 6719. (f) Sharma, P.; Bhat, S. V.; Prabhath, M. R. R.; Molino, A.; Nauha, E.; Wilson, D. J. D.; Moses, J. E. Org. Lett. 2018, 20, 4263. (g) Yavari, I.; Taheri, Z.; Naeimabadi, M.; Bahemmat, S.; Halvagar, M. R. Synlett 2018, 29, 918. (h) Voronin, V. V.; Ledovskaya, M. S.; Gordeev, E. G.; Rodygin, K. S.; Ananikov, V. P. J. Org. Chem. 2018, 83, 3819.

(33) Huisgen, R.; Seidel, M.; Sauer, J.; McFarland, J.; Wallbillich, G. J. Org. Chem. 1959, 24, 892.

(34) (a) Baldwin, J. E.; Hong, S. Y. Chem Commun. 1967, 1136a. (b) Baldwin, J. E.; Hong, S. Y. Tetrahedron 1968, 24, 3787.

(35) Miura, T.; Hagiwara, K.; Nakamuro, T.; Nagata, Y.; Oku, N.; $\begin{array}{llll}\text { Murakami, } & \text { M. } & \text { Chem. } & \text { Lett. }\end{array}$ https://doi.org/10.1246/cl.200634.

(36) Clovis, J.; Eckell, A.; Huisgen, R.; Sustmann, R. Chem. Ber. 1967, 100,60 .

(37) (a) Blasco, E.; Sugawara, Y.; Lederhose, P.; Blinco, J. P.; Kelterer, A.-M.; Barner-Kowollik, C. ChemPhotoChem, 2017, 1, 159. (b) Menzel, J. P.; Noble, B. B.; Lauer, A.; Coote, M. L.; Blinco, J. P.; Barner-Kowollik, C. J. Am. Chem. Soc. 2017, 139, 15812.

(38) Song, W.; Wang, Y.; Qu, J.; Madden, M. M.; Lin, Q. Angew. Chem. Int Ed. 2008, 47, 2832. 
(39) (a) Song, W.; Wang, Y.; Qu, J.; Lin, Q. J. Am. Chem. Soc. 2008, 130 9654. (b) Song, W.; Wang, Y.; Yu, Z.; Rivera Vera, C. I.; Qu, J.; Lin, Q. ACS Chem. Biol. 2010, 5, 875. (c) Yu, Z.; Pan, Y.; Wang, Z.; Wang, J.; Lin, Q. Angew. Chem. Int. Ed. 2012, 51, 10600. (d) Kamber, D. N.; Nazarova, L. A.; Liang, Y.; Lopez, S. A.; Patterson, D. M.; Shih, H.-W.; Houk, K. N.; Prescher, J. A. J. Am. Chem. Soc. 2013, 135, 13680.

(40) (a) Madden, M. M.; Rivera Vera, C. I.; Song, W.; Lin, Q. Chem. Commun. 2009, 5588. (b) Madden, M. M.; Muppidi, A.; Li, Z.; Li, X.; Chen, J.; Lin, Q. Bioorg. Med. Chem. Lett. 2011, 21, 1472.

(41) (a) An, P.; Lewandowski, T. M.; Lin, Q. ChemBioChem, 2018, 19, 1326. (b) Kulkarni, R. A.; Briney, C. A.; Crooks, D. R.; Bergholtz, S. E.; Mushti, C.; Lockett, S. J.; Lane, A. N.; Fan, T. W.-M.; Swenson, R. E.; Linehan, W. M.; Meier, J. L. ChemBioChem, 2019, 20, 360.

(42) (a) Lim, R.; Lin, Q. Chem Commun. 2010, 46, 1589. (b) Lim, R.; Lin, Q. Acc. Chem. Res. 2011, 44, 828. (c) Herner, A.; Lin, Q. Top. Curr. Chem. 2016, 374, 1. (d) Kumar, G. S.; Lin, Q. Chem. Rev. 2020, https://doi.org/10.1021/acs.chemrev.0c00799

(43) (a) Li, Z.; Qian, L.; Li, L.; Bernhammer, J. C.; Huynh, H. V.; Lee, J.-S.; Yao, S. Q. Angew. Chem. Int. Ed. 2016, 55, 2002. (b) Herner, A.; Marjanovic, J.; Lewandowski, T. M.; Marin, V.; Patterson, M.; Miesbauer, L.; Ready, D.; Williams, J.; Vasudevan, A.; Lin, Q. J. Am. Chem. Soc. 2016, 138, 14609. (c) Cheng, K.; Lee, J.-S.; Hao, P.; Yao, S. Q.; Ding, K.; Li, Z. Angew. Chem. Int. Ed. 2017, 56, 15044.

(44) Delaittre, G.; Goldmann, A. S.; Mueller, J. O.; Barner-Kowollik, C. Angew. Chem. Int. Ed. 2015, 54, 11388.

(45) (a) Darkow, R.; Yoshikawa, M.; Kitao, T.; Tomaschewski, G.; Schellenberg, J. J. Polym. Sci. A Polym. Chem. 1994, 32, 1657. (b) Dürr, C. J.; Lederhose, P.; Hlalele, L.; Abt, D.; Kaiser, A.; Brandau, S.; Barner-Kowollik, C. Macromolecules 2013, 46, 5915. (c) Mueller, J. O.; Voll, D.; Schmidt, F. G.; Delaittre, G.; Barner-Kowollik, C. Chem. Commun. 2014, 50, 15681. (d) Mueller, J. O.; Guimard, N. K.; Oehlenschlaeger, K. K.; Schmidt, F. G.; Barner-Kowollik, C. Polym. Chem. 2014, 5, 1447. (e) Hiltebrandt, K.; Pauloehrl, T.; Blinco, J. P.; Linkert, K.; Börner, H. G.; Barner-Kowollik, C. Angew. Chem. Int. Ed. 2015, 54, 2838. (f) Hufendiek, A.; Carlmark, A.; Meier, M. A. R.; Barner-Kowollik, C. ACS Macro Lett. 2016, 5, 139. (g) Estupiñán, D.; Barner-Kowollik, C.; Barner, L. Angew. Chem. Int. Ed. 2018, 57, 5925.

(46) (a) Dietrich, M.; Delaittre, G.; Blinco, J. P.; Inglis, A. J.; Bruns, M.; Barner-Kowollik, C. Adv. Funct. Mater. 2012, 22, 304. (b) Blasco, E.; Piñol, M.; Oriol, L.; Schmidt, B. V. K. J.; Welle, A.; Trouillet, V.; Bruns, M.; Barner-Kowollik, C. Adv. Funct. Mater. 2013, 23, 4011. (c) Rodriguez-Emmenegger, C.; Preuss, C. M.; Yameen, B.; PopGeorgievski, O.; Bachmann, M.; Mueller, J. O.; Bruns, M.; Goldmann, A. S.; Bastmeyer, M.; Barner-Kowollik, C. Adv. Mater. 2013, 25, 6123. (d) Tischer, T.; Rodriguez-Emmenegger, C.; Trouillet, V.; Welle, A.; Schueler, V.; Mueller, J. O.; Goldmann, A. S.; Brynda, E.; Barner-Kowollik, C. Adv. Mater. 2014, 26, 4087. (e) Hufendiek, A.; Barner-Kowollik, C.; Meier, M. A. R. Polym. Chem. 2015, 6, 2188. (f) Vonhören, B.; Roling, O.; Buten, C.; Körsgen, M.; Arlinghaus, H. F.; Ravoo, B. J. Langmuir 2016, 32, 2277. (g) Buten, C.; Lamping, S.; Körsgen, M.; Arlinghaus, H. F.; Jamieson, C.; Ravoo, B. J. Langmuir 2018, 34, 2132. (h) Delafresnaye, L.; Zaquen, N.; Kuchel, R. N.; Blinco, J. P.; Zetterlund, P. B.; Barner-Kowollik, C. Adv. Funct. Mater. 2018, 28, 1800342.

(47) Livingstone, K.; Bertrand, S.; Mowat, J.; Jamieson, C. Chem. Sci. 2019, 10, 10412

(48) Green, L.; Livingstone, K.; Bertrand, S.; Peace, S.; Jamieson, C. Chem. Eur. J. 2020, https://doi.org/10.1002/chem.202002896

(49) (a) Wang, Y.; Hu, W. J.; Song, W.; Lim, R. K. V.; Lin, Q. Org. Lett. 2008, 10, 3725. (b) Yu, Z.; Ho, L.; Wang, Z.; Lin, Q. Bioorg. Med. Chem. Lett. 2011, 21, 5033. (c) An, P.; Yu, Z.; Lin, Q. Chem. Commun. 2013, 49, 9920. (d) An, P.; Yu, Z.; Lin, Q. Org. Lett. 2013 15, 5496. (e) Yu, Z.; Ohulchankyy, T. Y.; An, P.; Prasad, P. N.; Lin, Q. J. Am. Chem. Soc. 2013, 135, 16766.

(50) Lederhose, P.; Wüst, K. N. R.; Barner-Kowollik, C.; Blinco, J. P. Chem. Commun. 2016, 52, 5928. (b) Lederhose, P.; Chen, Z.; Müller, R.; Blinco, J. P.; Wu, S.; Barner-Kowollik, C. Angew. Chem. Int. Ed. 2016, 55, 12195.
(51) (a) Stewart, F. H. C.; Chem. Rev. 1964, 64, 129. (b) Kuo, C.-N.; Wang, S.-P.; Yeh, M.-Y.; Tien, H.-J. J. Chin. Chem. Soc. 1992, 39, 641. (c) Browne, D. L.; Harrity, J. P. A. Tetrahedron 2010, 66, 553. (d) Cherepanov, I. A.; Moiseev, S. K. In Advances in Heterocyclic Chemistry, Vol. 131; Scriven, E. F. V.; Ramsden, C. A., Ed.; Elsevier: Amsterdam, 2020, 49. (e) Porte, K.; Riomet, M.; Figliola, C.; Audisio, D.; Taran, F. Chem. Rev. 2020, https://doi.org/10.1021/acs.chemrev.0c00806

(52) (a) Decuypére, E.; Plougastel, L.; Audisio, D.; Taran, F. Chem. Commun. 2017, 53, 11515. (b) Hladíková, V.; Váňa, J.; Hanusek, J. Beilstein J. Org. Chem. 2018, 14, 1317.

(53) Krauch, C.; Kuhls, J.; Piek, H. Tetrahedron Lett. 1966, 7, 4043.

(54) (a) Chinone, A.; Huseya, Y.; Ohta, M. Bull. Chem. Soc. Jpn. 1970, 43, 2650. (b) Huseya, Y.; Chinone, A.; Ohta, M. Bull. Chem. Soc. Jpn. 1971, 44, 1667. (c) Angadiyavar, C. S.; George, M. V. J. Org. Chem. 1971, 36, 1589. (d) Gotthardt, H.; Reiter, F. Tetrahedron Lett. 1971, 12, 2749. (e) Märky, M.; Hansen, H.; Schmid, H. Helv. Chem. Acta 1971, 54, 1275.

(55) (a) Zhang, L.; Zhang, X.; Yao, Z.; Jiang, S.; Deng, J.; Li, B.; Yu, Z. J. Am. Chem. Soc. 2018, 140, 7390. (b) Zhang, X.; Wu, X.; Jiang, S.; Gao, J.; Yao, Z.; Deng, J.; Zhang, L.; Yu, Z. Chem. Commun. 2019, 55, 7187. (c) Deng, J.; Wu, X.; Guo, G.; Zhao, X.; Yu, Z. Org. Biomol. Chem. 2020, 18, 5602 .

(56) (a) Kaji, E.; Harada, K.; Zen, S. Chem. Pharm. Bull. 1978, 26, 3254 (b) Roscales, S.; Plumet, J. Org. Biomol. Chem. 2018, 16, 8446. (c) Plumet, J. ChemPlusChem 2020, 85, 2252-2271.

(57) Mandal, D. Pericyclic Chemistry, Elsevier, Amsterdam, 2018.

(58) (a) Paton, R. M. Comprehensive Heterocyclic Chemistry, Vol. 6-7, Elsevier, 1984, 393. (b) Yu, Z.; Caramella, P.; Houk, K. N. J. Am. Chem. Soc. 2003, 125, 15420. (c) Pasinszki, T.; Hajgató, B.; Havasi, B.; Westwood, N. P. C. Phys. Chem. Chem. Phys. 2009, 11, 5263.

(59) (a) Grundmann, C.; Dean, J. M. J. Org. Chem. 1965, 30, 2809. (b) Krayushkin, M. M.; Loktionov, A. A.; Belenkii, L. I. Chem. Heterocycl. Compd.,1988, 24, 850.

(60) (a) Sicard, G.; Baceiredo, A.; Bertrand, G. J. Am. Chem. Soc. 1988 110, 2663. (b) Granier, M.; Baceiredo, A.; Bertrand, G. Angew. Chem. Int. Ed. 1988, 27, 1350. (c) Castan, F.; Baceiredo, A.; Bertrand, G. Angew. Chem. Int. Ed. 1989, 28, 1250. (d) Granier, M.; Baceiredo, A.; Dartiguenave, M.; Menu, M.-J.; Bertrand, G. J. Am. Chem. Soc. 1990, 112, 6277. (e) Granier, M.; Baceiredo, A.; Huch, V.; Veith, M.; Bertrand, G. Inorg. Chem. 1991, 30, 1161. (f) Arthur, M.; Goodwin, H.; Baceiredo, A.; Dillon, K. B.; Bertrand, G. Organometallics, 1991, 10, 3205. (g) Réau, R.; Veneziani, G.; Dahan, F.; Bertrand, G. Angew. Chem. Int. Ed. 1992, 31, 439. (h) Réau, R.; Veneziani, G.; Bertrand, G. J. Am. Chem. Soc. 1992, 114, 6059. (i) Leue, C.; Réau, R.; Neumann, B.; Stammler, H.-G.; Jutzi, P.; Bertrand, G. Organometallics 1994, 13, 436. (j) Dubau, N.; Arthur, M.-P.; Dahan, F.; Baceiredo, A.; Bertrand, G. Organometallics 1994, 13, 2913. (j) Emig, N.; Gabbaï, F. P.; Krautscheid, H.; Réau, R., Bertrand, G. Angew. Chem. Int. Ed. 1998, 37, 989.

(61) For early reviews, see (a) C. Grundmann in Houben-Weyl, "Methoden der Organischen Chemie," Vol. X/3, 4th ed; Müller, E., Ed.; Georg Thieme: Stuttgart, 1965. (b) Grundmann C., Grünanger P. Preparation In: The Nitrile Oxides. Organische Chemie in Einzeldarstellungen. Vol 13.; Springer: Berlin, Heidelberg. 1991.

(62) (a) Christl, M.; Huisgen, R. Chem. Ber. 1973, 106, 3345. For early examples, see (b) Grundmann, C., Dean, J. M. Angew. Chem. 1964, 76, 682. (c) Abramovitch, R. A. and Saha, J. G. in Advances in Heterocyclic Chemistry, Vol. 6, A. R. Katritzky, A. R.; Boulton, A. J. Ed., Academic Press Inc.: New York, N. Y., 1966. (d) Grundmann, C.; Richter, R. J. Org. Chem. 1968, 33, 476. For significant advances, see (e) Liu, K.; Shelton, B. R.; Howe, R. K. J. Org. Chem. 1980, 45, 3916. (f) Lee, G. A. Synthesis 1982, 508. (g) Larsen, K. E.; Torsell, K. B. G. Tetrahedron 1984, 40, 2985. (h) Corbett, D. F. J. Chem. Soc., Perkin Trans. 1, 1986, 421. (i) Kim, J.; Ryu, E. Synth. Commun. 1990,20, 1373. (j) V. Jager, P. A. Colinas in The Chemistry of Heterocyclic Compounds: Synthetic Applications of 1,3-Dipolar Cycloaddition Chemistry Towards Heterocycles and Natural products, Vol. 59; Padwa, A.; Pearson, W. H., Eds; John 
Wiley \& Sons: New York, 2002. (k) Ye, Y.; Zheng, Y.; Xu, G.-Y.; Liu, L.-Z. Heteroatom Chem. 2003, 14, 254. (l) Kumar, V.; Kaushik, M. P. Tetrahedron Lett. 2006, 47, 1457. For recent examples, see: (m) Ledovskaya, M. S.; Rodygina, K. S.; Ananikov, V. P. Org. Chem. Front. 2018, 5, 226. (n) Uceta, H.; Vizuete, M.; Carrillo, J. R.; Barrejón, M.; Fierro, J. L. G.; Prieto, M. P.; Langa, F. Chem. Eur. J. 2019, 25, 14644. (o) Shanmugasundaram, M.; Senthilvelan, A.; Kore, A. R. Tetrahedron Lett. 2020, 61, 152464. Hydroximoyl fluorides have recently been reported: (p) Gao, F.-T.; Fang, Z.; Su, R.-R.; Ruia, P.-X.; Hu, X.-G. Org. Biomol. Chem. 2018, 16, 9211.

(63) (a) Just, G.; Dahl, K. Tetrahedron 1968, 24, 5251. For significant advances, see (b) Giurg, M.; Młochowski, J. Pol. J. Chem., 1997, 71, 1093. (c) Kiegiel, J.; Poplawska, M.; Jóźwik, J.; Kosior, M.; Jurczak, J. Tetrahedron Lett. 1999, 40, 5605 and references cited herein for other previously reported reagents for direct oxidation. (d) Kudyba, I.; Jóźwik, J.; Romanski, J.; Raczko, J.; Jurczak, J. Tetrahedron: Asymmetry 2005, 16, 2257. For recent examples, see: (e) Bhosale, S.; Kurhade, S.; Prasad, U. V.; Palle, V. P.; Bhuniya, D. Tetrahedron Lett. 2009, 50, 3948. (f) Bhosale, S.; Kurhade, S.; Vyas, S.; Palle, V. P.; Bhuniya, D. Tetrahedron 2010, 66, 9582.

(64) (a) Mukaiyama, T.; Hoshino, T. J. Am. Chem. Soc. 1960, 82, 5339. For significant advances, see: (b) Shimizu, T.; Hayashi, Y.; Teramura, K. Bull. Chem. Soc. Jpn. 1984, 57, 2531. (c) Shimizu, T.; Hayashi, Y.; Shibafuchi, H.; Teramura, K. Bull. Chem. Soc. Jpn. 1986, 59, 2827. (d) Basel, Y.; Hassner, A. Synthesis 1997, 309. (e) Maugein, N.; Wagner, A.; Mioskowski, C. Tetrahedron Lett. 1997, 38, 1547. (f) Adams, J. P.; Paterson, J. R. J. Chem. Soc., Perkin Trans. 1, 2000, 3695. (g) Giacomelli, G.; De Luca, L.; Porcheddu, A. Tetrahedron 2003, 59, 5437. (h) I. N. N. Namboothiri, N. Rastogi, in Synthesis of Heterocycles via Cycloaddition (Topics in Heterocycl. Chem.); Springer-Verlag: Berlin, Heidelberg, 2008. For recent examples, see (i) Chary, R. G.; Reddy, G. R.; Ganesh, Y. S. S.; Prasad, K. V.; Raghunadh, A.; Krishna, T.; Mukherjee, S.; Pal, M. Adv. Synth. Catal. 2014, 356, 160. (j) Choe, H.; Cho, H.; Ko, H.; Lee, J. Org. Lett. 2017, 19, 6004. (k) Zatsikha, Y. V.; Didukh, N. O.; Swedin, R. K.; Yakubovskyi, V. P.; Blesener, T. S.; Healy, A. T.; Herbert, D. E.; Blank, D. A.; Nemykin, V. N.; Kovtun, Y. P. Org. Lett. 2019, 21, 5713. (l) Umemoto, N.; Imayoshi, A.; Tsubaki, K. Tetrahedron. Lett., 2020, 61, 152213.

(65) (a) Grundmann, C., Dean, J. M. Angew. Chem. 1964, 76, 682. (b) Grundmann, C.; Dean, J. M. J. Org. Chem. 1965, 30, 2809. (c) Chatterjee, N.; Pandit, P.; Halder, S.; Patra, A.; Maiti, D. K. J. Org. Chem. 2008, 73, 7775.
(66) Das, B.; Holla, H.; Mahender, G.; Banerjee, J.; Reddy, M. R. Tetrahedron Lett. 2004, 45, 7347.

(67) For examples, see (a) Das, B.; Holla, H.; Mahender, G.; Venkateswarlu, K.; Bandgar, B. P. Synthesis 2005, 10, 1572. (b) Prakash, O.; Pannu, K. ARKIVOC 2007, 28. (c) Jadhav, R. D.; Mistry, H. D.; Motiwala, H.; Kadam, K. S.; Kandre, S.; Gupte, A.; Gangopadhyay, A. K.; Sharma, R. J. Heterocycl. Chem. 2013, 50, 774. (d) Jawalekar, A. M.; Reubsaet, E.; Rutjes, F. P. J. T.; van Delft, F. L. Chem. Commun. 2011, 47, 3198. Recent examples: (e) Singhal, A.; Parumala, S. K. R.; Sharma, A.; Peddinti, R. K. Tetrahedron Lett. 2016, 57, 719. (f) Yoshimura, A.; Nguyen, K. C.; Rohde, G. T.; Postnikov, P. S.; Yusubov, M. S.; Zhdankin. V. V. J. Org. Chem. 2017, 82, 11742. (g) Subramanian, P.; Kaliappan, K. P. Chem. Asian J. 2018, 13, 2031.

(68) (a) Mendelsohn, B. A.; Lee, S.; Kim, S.; Teyssier, F.; Aulakh. V. S.; Ciufolini, M. A. Org. Lett. 2009, 11, 1539. (c) Jen, T.; Mendelsohn, B. A.; Ciufolini, M. A. J. Org. Chem. 2011, 76, 728.

(69) (a) Frie, J. L.; Jeffrey, C. S.; Sorensen, E. J. Org. Lett. 2009, 11, 5394. (b) Schneider, M.; Richter, M. J. R.; Carreira, E. M. J. Am. Chem. Soc. 2020, 142, 17802.

(70) (a) Yoshimura, A.; Middleton, K. R.; Todora, A. D.; Kastern, B. J.; Koski, S. R.; Maskaev, A. V.; Zhdankin, V. V. Org. Lett. 2013, 15, 4010. (b) Han, L.; Zhang, B.; Xiang, C.; Yan, J. Synthesis 2014, 46, 503. (c) Xiang, C.; Li, T.; Yan, J. Synth. Commun. 2014, 44, 682.

(71) Yoshimura, A.; Nguyen, K. C.; Rohde, G. T.; Saito, A.; Yusubov, M. S.; Zhdankin, V. V. Adv. Synth. Catal. 2016, 358, 2340.

(72) (a) Chen, R.; Zhao, Y.; Fang, S.; Long, W.; Sun, H.; Wan, X. Org. Lett. 2017, 19, 5896. (b) Chen, R.; Ogunlana, A. A.; Fang, S.; Long, W.; Sun, H.; Bao, X.; Wan, X. Org. Biomol. Chem. 2018, 16, 4683

(73) Wang, X.; Zhu, L.; Liu, P.; Wang, X.; Yuan, H.; Zhao, Y. J. Org. Chem. 2019, 84, 16214

(74) Zhang, X.; He, X.; Yan, N.; Zheng, H.; Hu, X. J. Org. Chem. 2020, 85, 15726.

(75) Dai, P.; Tan, X.; Luo, Q.; Yu, X.; Zhang, S.; Liu, F.; Zhang, W.-H. Org. Lett. 2019, 21, 5096.

(76) (a) Raihan, M. J.; Kavala, V.; Kuo, C.; Raju, B. R.; Yao, C. Green Chem. 2010, 12, 1090. (b) Kesornpun, C.; Aree, T.; Mahidol, C.; Ruchirawat, S.; Kittakoop, P. Angew.Chem. Int. Ed. 2016, 55, 3997.

(77) Zhao, G.; Liang, L.; Wen, C. H. E.; Tong, R. Org. Lett. 2019, 21, 315.

(78) Muri, D.; Bode, J. W.; Carreira, E. M. Org. Lett., 2000, 2, 539.

(79) Carloni, L. Mohnani, S.; Bonifazi, D. Eur. J. Org. Chem. 2019, 2019, 7322.

(80) Svejstrup, T. D.; Zawodny, W.; Douglas, J. J.; Bidgeli, D.; Sheikh, N. S.; Leonori, D. Chem. Commun. 2016, 52,12302.

Keith Livingstone received his MChem in Chemistry with Drug Discovery at the University of
Strathclyde, Glasgow in June 2016. In August 2020, he completed his PhD studies focusing on the
reactivity profiles of the nitrile imine 1,3-dipole, mentored by Dr. Jamieson at Strathclyde. He currently
works as a post-doctoral researcher at Westfälische Wilhelms-Universität Münster under the
supervision of Prof. Dr. Ryan Gilmour.




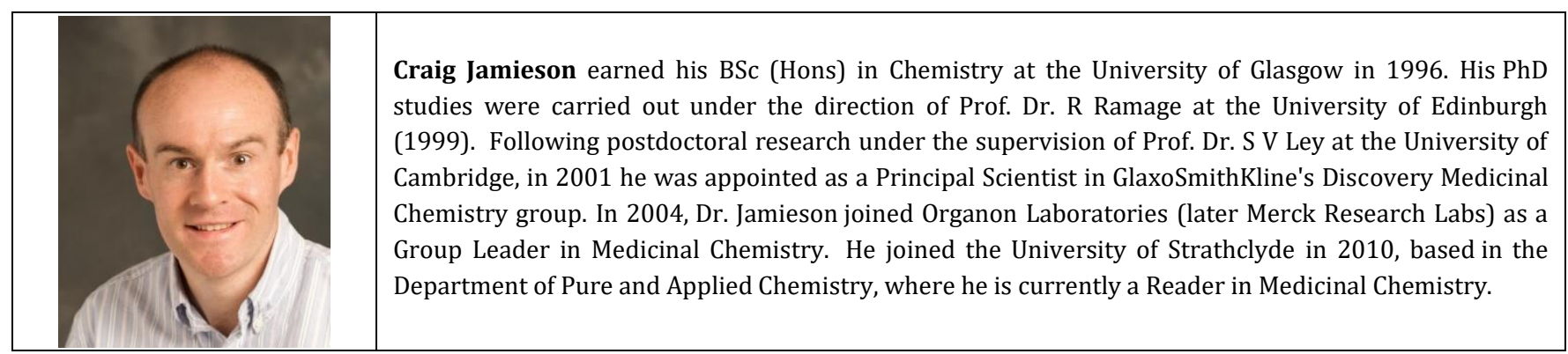

For Reviews, include photos and short biographical text for all authors. If the photo is of a group of people, specify who is shown where.

For Short Reviews, restrict the photo and biographical text to the main (starred) author(s). If the photo displays coworkers, however, they can be mentioned briefly within the main author's short biography.

Photographs (.jpg or .tif format) must be a minimum of $300 \mathrm{dpi}$ in order to reproduce well in print.

\section{Checklist (have these on hand for manuscript submission in ScholarOne):}

- cover letter, including a statement of the work's significance

- full mailing address, telephone and fax numbers, and e-mail address of the corresponding author

- email address for each author

- original Word file

- original graphics files zipped into one zip file

- eye-catching graphical abstract as an individual file

- 5-8 key words

\section{Useful links:}

- SYNTHESIS homepage

- SYNTHESIS information and tools for authors

- Graphical abstract samples (PDF file download)

- What is "Primary Data"?

- ScholarOne (manuscript submission) 